Supplement of Geosci. Model Dev., 13, 2095-2107, 2020

https://doi.org/10.5194/gmd-13-2095-2020-supplement

(c) Author(s) 2020. This work is distributed under

the Creative Commons Attribution 4.0 License.

(c) (1)

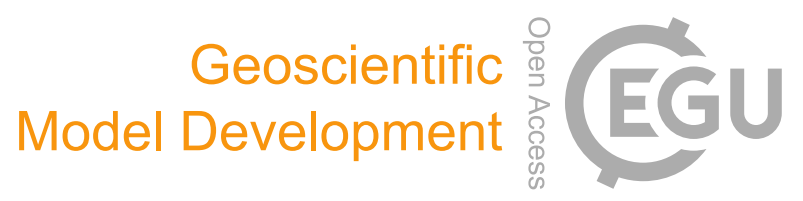

Supplement of

\title{
Bayesian spatio-temporal inference of trace gas emissions using an integrated nested Laplacian approximation and Gaussian Markov random fields
}

Luke M. Western et al.

Correspondence to: Luke M. Western (luke.western@bristol.ac.uk)

The copyright of individual parts of the supplement might differ from the CC BY 4.0 License. 


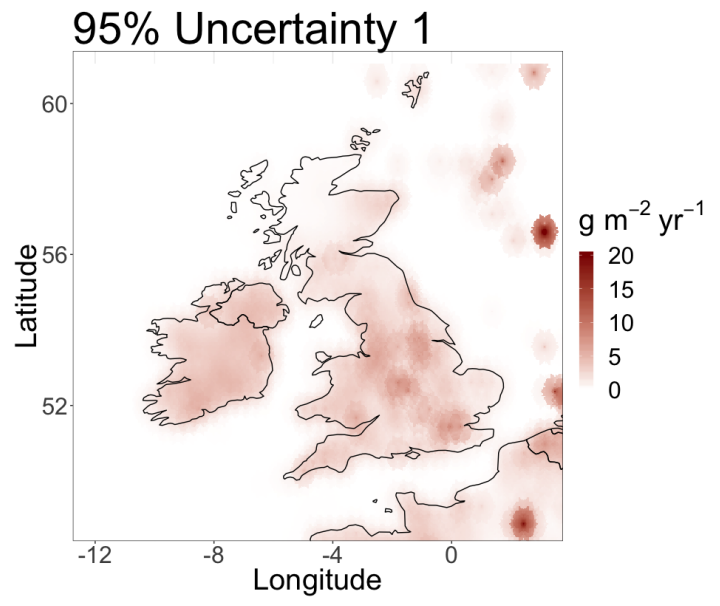

(a) First time period.

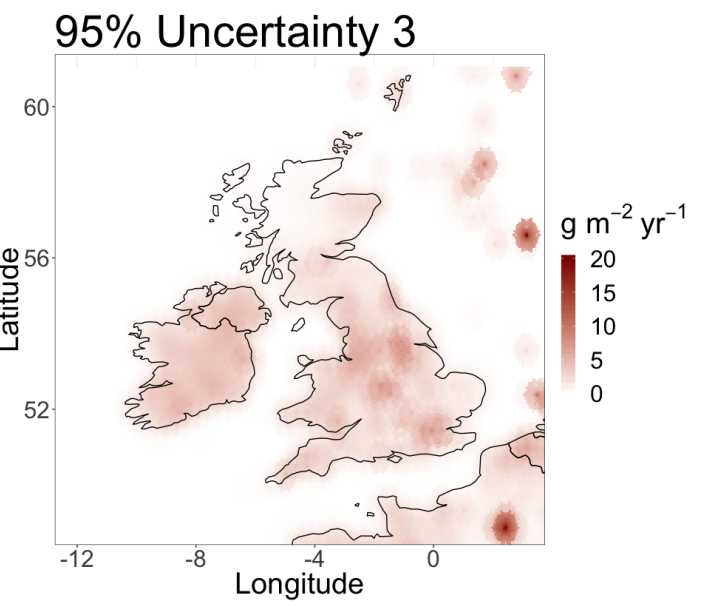

(c) Third time period.

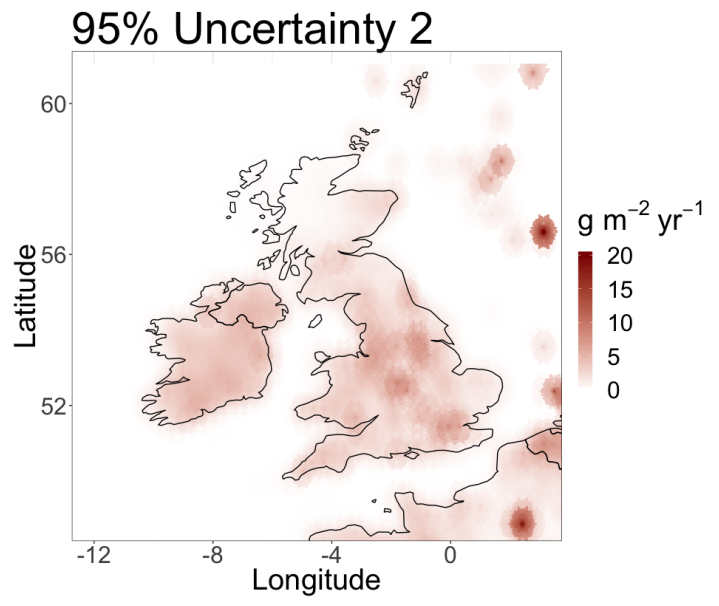

(b) Second time period.

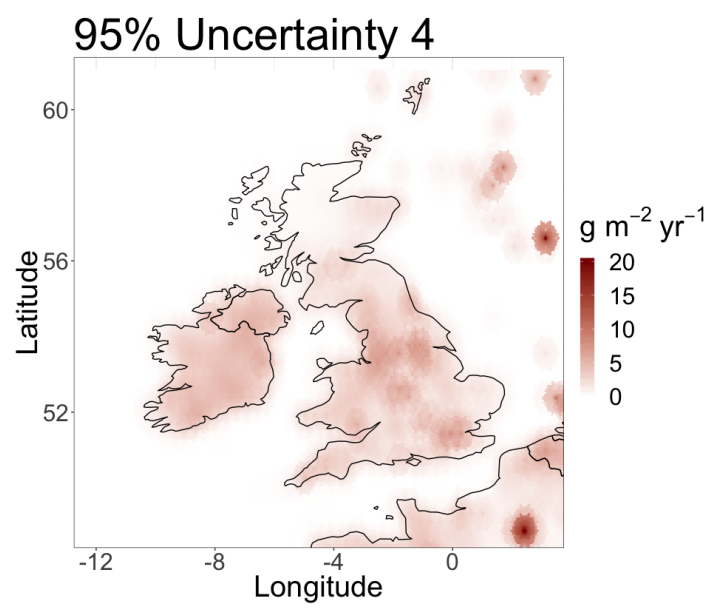

(d) Fourth time period.

Figure S1. Time correlated $95 \%$ posterior uncertainty in the deviation of emissions from the simulated prior mean, simulated using a Matérn field. 


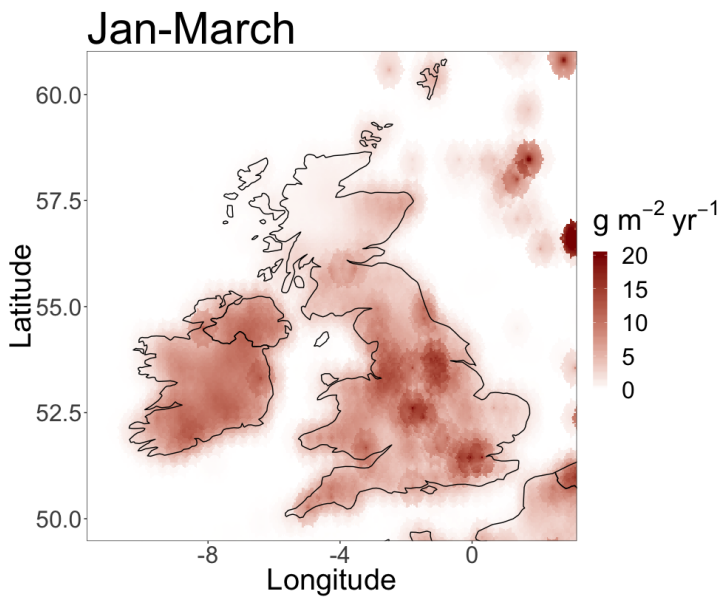

(a) January to March

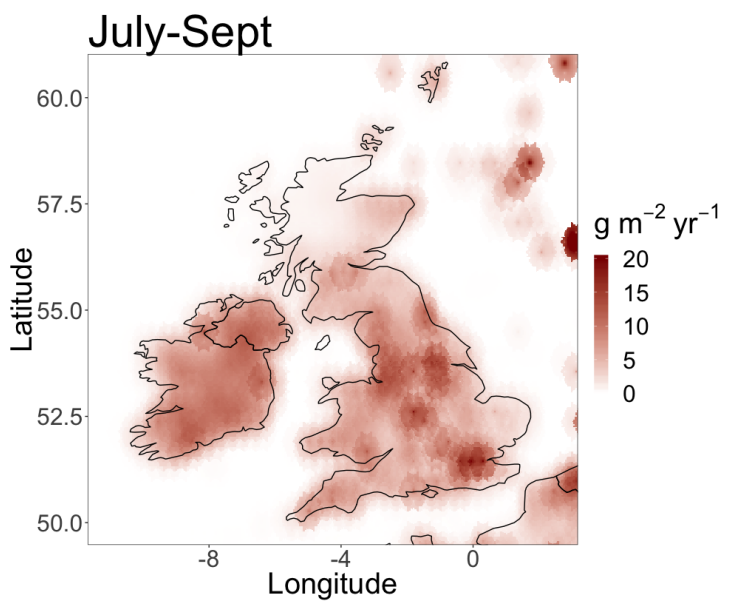

(c) July to September

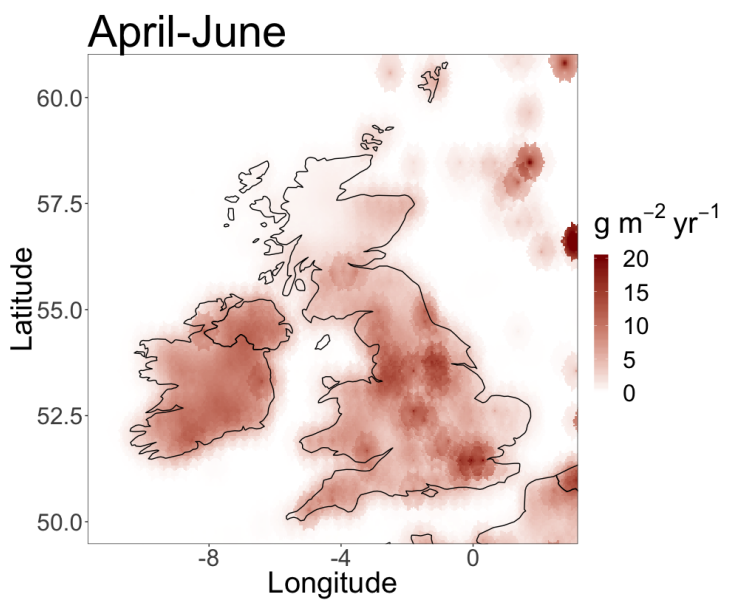

(b) April to June

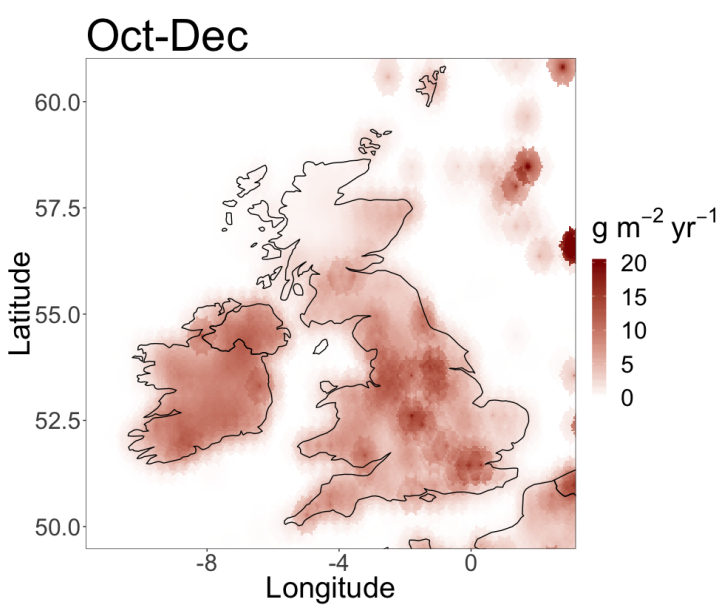

(d) October to December

Figure S2. Time correlated $95 \%$ posterior uncertainty in the difference in methane emissions from the EDGAR inventory for the UK in 2014. 